\title{
CARACTERIZAÇÃO DOS PRINCIPAIS ATIVOS DO SISTEMA REGIONAL DE INOVAÇÃO FLUMINENSE E DESAFIOS PARA UMA AGENDA DE DESENVOLVIMENTO PÓS-COVID
}

\author{
Guilherme de Oliveira Santos \\ ORCID: https://orcid.org/0000-0001-6038-4745 \\ Renata Lèbre La Rovere \\ ORCID: https://orcid.org/0000-0001-5912-5500 \\ Recebido em: 08/04/2021 \\ Publicado em: 30/06/2021
}

\section{RESUMO}

A severa crise econômica e social que afeta o Estado do Rio de Janeiro desde 2014 foi intensificada pelos efeitos trazidos pela crise sanitária iniciada em março de 2020. Esta convergência de crises restringe as possibilidades de desenvolvimento do estado. O estímulo à inovação e a resolução de desafios societais complexos são caminhos para a superação do atual cenário. Neste sentido, este artigo tem como objetivos: i) realizar uma caracterização dos principais ativos do Sistema Regional de Inovação fluminense, com base no levantamento de dados primários e secundários associado ao uso de estatística descritiva; ii) refletir sobre os desafios que o estado possui para construir uma agenda de desenvolvimento pós Covid-19. Os resultados apontam que o SRI possui ativos financeiros, humanos e tecnológicos relevantes, contudo precisa articular melhor os subsistemas de geração e aplicação do conhecimento; aumentar a taxa de inovação da economia; e se desprender da puramente lógica setorial e de vocações, utilizando seus ativos para elaborar uma política de inovação orientada por missões, que articule diversos atores e tecnologias e tenha como foco solução de grandes desafios societais por meio da geração, aplicação e difusão do conhecimento científico-tecnológico.

PALAVRAS-CHAVE: Sistema Regional de Inovação; Estado do Rio de Janeiro; Desafios; Desenvolvimento.

\section{CHARACTERIZATION OF THE MAIN ASSETS OF THE REGIONAL FLUMINSE INNOVATION SYSTEM AND CHALLENGES FOR A POST-COVID DEVELOPMENT AGENDA}

\begin{abstract}
The severe social and economic crisis of the state of Rio de Janeiro since 2014 has been enhanced by the effects of the sanitary crisis of March 2020. This crisis convergence limits possibilities of development of the state. To stimulate innovation and to solve complex societal challenges are possible solutions to surpass the present difficulties. In this sense this

\footnotetext{
${ }^{1}$ Assessor da diretoria de tecnologia da FAPERJ e pesquisador do Grupo de Economia da Inovação do Instituto de Economia da UFRJ

${ }^{2}$ Professora titular e pesquisadora do Grupo de Economia da Inovação do Instituto de Economia da UFRJ
} 
paper has as main objectives: i) to describe the main assets of the Regional Innovation System of Rio de Janeiro, based on primary and secondary data and descriptive statistics; ii) to identify the challenges the state has to build a development agenda after the Covid 19 crisis. Results suggest that Rio's RIS has relevant financial, and technological resources. However, the state needs to improve links between knowledge generation and knowledge application subsystems, to increase innovation and also to get free of the sectoral and vocation logic, moving towards a mission-oriented innovation policy. This policy would articulate the main actors and technologies, with focus in the solution of great societal challenges resulting from the generation, application and diffusion of scientific and tecnological knowledge.

KEY WORDS: Regional Innovation System; Rio de Janeiro State; Challenges; Development.

\section{CARACTERIZACIÓN DE LOS PRINCIPALES ACTIVOS DEL SISTEMA DE INNOVACIÓN REGIONAL FLUMINSE Y DESAFÍOS PARA UNA AGENDA DE DESARROLLO POST-COVID}

\section{RESUMEN}

La severa crisis económica y social que ha afectado al estado de Río de Janeiro desde 2014 se ha visto agravada por los efectos provocados por la crisis de salud iniciada en marzo de 2020. Esta convergencia de crisis restringe las posibilidades de desarrollo del estado. Estimular la innovación y resolver desafíos sociales complejos son formas de superar el escenario actual. En este sentido, este artículo tiene como objetivo: i) caracterizar los principales activos del Sistema Regional de Innovación de Río de Janeiro, a partir de la recolección de datos primarios y secundarios asociados al uso de estadística descriptiva; ii) reflexionar sobre los desafíos que tiene el estado para construir una agenda de desarrollo post-Covid-19. Los resultados muestran que el SRI tiene activos financieros, humanos y tecnológicos relevantes, sin embargo necesita articular mejor los subsistemas de generación y aplicación de conocimiento; aumentar la tasa de innovación en la economía; y desvincularse de la lógica y vocaciones puramente sectoriales, utilizando sus activos para desarrollar una política de innovación orientada a la misión, que articule diversos actores y tecnologías y se enfoque en la solución de los principales desafíos sociales a través de la generación, aplicación y difusión del conocimiento científico-tecnológico

PALABRAS CLAVE: Sistema Regional de Innovación; Estado de Rio de Janeiro; Desafíos; Desarrollo.

\section{INTRODUÇÃO}

Desde antes da pandemia do novo coronavírus, o Estado do Rio de Janeiro (ERJ) já enfrentava uma severa crise econômica e social, que se intensificou a partir de 2014. A crise sanitária vivida desde março de 2020 agravou algumas tendências estruturais que afetavam fortemente a dinâmica econômica fluminense há mais de duas décadas, incluindo o enfraquecimento de elos das cadeias produtivas (Sobral, 2017), aumento da informalidade do mercado de trabalho (Osório e Versiani, 2020), baixa taxa de inovação do tecido produtivo 
(Marcellino e Santos, 2017), especialmente de pequenas e médias empresas, e fragilidade fiscal do estado.

Esta convergência entre múltiplas crises - sanitária, social e econômica -, que tem no desemprego, penúria fiscal e enfraquecimento do tecido produtivo seus efeitos mais perversos, ao mesmo tempo em que limita as possibilidades, também cria oportunidades que podem ser exploradas pelo estado. Neste sentido, o imperativo da diversificação econômica e a necessidade de responder a desafios societais complexos, como é o caso dos impactos multidimensionais gerados pela pandemia do Covid-19, podem ser atendidos através do estímulo à inovação no conjunto da economia fluminense, criando um contexto propício à construção de uma agenda de desenvolvimento capaz de articular diferentes atores.

Partindo do princípio de que a inovação resulta de um processo sistêmico e interativo que se materializa em um ambiente institucional e socioeconômico caracterizado por particularidades ligadas ao território, a utilização do conceito de Sistemas Regionais de Inovação, proposto por autores neo-schumpeterianos, se mostra adequada para refletir sobre as potencialidades e desafios que o estado possui para construir uma agenda de desenvolvimento pós Covid-19. Como observado por Lastres e Cassiolato (2020, p.289), Celso Furtado "repetidamente advertiu que as políticas de desenvolvimento que ignoram a dimensão territorial tendem a agravar as exclusões e as disparidades econômicas, sociais e políticas" e também apresenta uma visão sistêmica de ciência, tecnologia e inovação (idem, p.293). Esta visão sistêmica proposta por Celso Furtado para refletir sobre a realidade brasileira e sua capacidade de produzir ciência, tecnologia e inovação converge com os pressupostos da corrente neo-schumpeteriana, a qual apresenta convergências e complementaridades com o pensamento estruturalista de Celso Furtado (Guimarães et $a l, .2007)$.

Deste modo, este artigo tem dois objetivos complementares. Em primeiro lugar será realizada uma caracterização dos principais ativos do Sistema Regional de Inovação Fluminense, incluindo suas competências, redes e dinâmica inovativa. Para tanto, iremos utilizar o modelo teórico de SRI proposto na literatura, enfatizando os subsistemas de geração e difusão do conhecimento e de Produção e Inovação, bem como a interação entre os mesmos. A caracterização de cada um dos subsistemas e de sua interação será feita a partir do levantamento de dados secundários em publicações e bases de dados oficiais associado ao uso de estatística descritiva. Em segundo lugar, vamos refletir sobre os desafios que o estado possui para construir uma agenda de desenvolvimento pós Covid-19 a partir desta caracterização. 
O artigo, portanto, está organizado em quatro seções, além desta introdução. A seção 2 traz o referencial teórico de Sistemas Regionais de Inovação, apresentando o modelo teórico utilizado na caracterização proposta. A terceira seção detalha a metodologia, explicitando os dados utilizados para analisar cada categoria. A seção 4 expõe os resultados da caracterização das dimensões do SRI examinadas. A seção 5 apresenta discussão sobre os desafios do SRI para o desenvolvimento pós Covid-19. E a seção 6 traz as considerações finais.

\section{REFERENCIAL TEÓRICO: SISTEMAS REGIONAIS DE INOVAÇÃO}

O conceito de Sistema Regional de Inovação (SRI) se estrutura a partir de dois eixos: a percepção de que a inovação é um processo sistêmico e interativo (Lundvall, 1992); e os benefícios gerados pela concentração das atividades econômicas e da proximidade geográfica (Cooke et al., 2004; Boschma, 2005). De forma sintética, o SRI pode ser definido como "um conjunto de interesses públicos e privados, instituições formais e outras organizações que, interagindo entre si, funcionam de forma a conduzir à geração, uso e difusão do conhecimento em uma determinada região" (Doloreux e Parto, 2005, p. 134-135).

Além de abranger uma ampla gama de atores envolvidos nos processos de inovação, incluindo empresas, instituições científico-tecnológicas, agências de fomento, gestores públicos, instituições financeiras e organizações intermediárias (Doloreux e Gomez, 2016), os sistemas regionais de inovação também abarcam os padrões socioculturais relativos à atividade inovativa incorporados ao contexto regional, assim como as políticas que permitem que tanto as firmas quanto os sistemas evoluam ao longo do tempo (Urraya, 2010). Cabe observar que o conceito fornece elementos de reflexão para analisar tanto políticas explícitas quanto políticas implícitas de apoio à inovação. Como apontado por Herrera (2011), o problema dos países latino-americanos no que se refere às políticas de ciência e tecnologia não se resume às fragilidades presentes nas políticas explícitas, mas na dificuldade de se reconhecer as políticas implícitas, as quais, apesar de carecer de estruturação formal, “expressam a demanda científica e tecnológica do 'projeto nacional' vigente em cada país" (Herrera, 2011,p.162).

Em relação aos componentes do sistema, pode-se pensar o SRI como sendo formado por subsistemas com coerência e dinâmica próprias. Os subsistemas mencionados são quatro e compreendem: a demanda; a produção, que articula e utiliza tecnologias e conhecimentos; as organizações responsáveis que impulsionam a geração e difusão desses conhecimentos; e, por fim, as instituições capazes de formular e implementar políticas. As conexões entre esses 
subsistemas, por seu turno, contribuem para determinar a vitalidade sistema em termos de inovação e da ocorrência do aprendizado interativo (Cooke, 1998). A Figura 1 busca representar esquematicamente um SRI.

Complementarmente, um SRI deve ser entendido como um sistema aberto uma vez que a inserção da região no contexto nacional e internacional é importante. O SRI se relaciona com dois contextos mais amplos: o do Sistema Nacional de Inovação (SNI), que inclui infraestrutura, arcabouço institucional (legal e regulatório), sistema financeiro e sistema de educação; e do Sistema Global de Inovação, que engloba cadeias globais de valor, empresas transnacionais, leis internacionais, acordos comerciais, regulamentações financeiras e direitos de propriedade intelectual. Esta dinâmica é ainda mais crítica no contexto latino-americano, na medida em que as dinâmicas de inovação e aprendizagem da região são influenciadas por redes globais e pela distribuição assimétrica de poder (Fernandez e Comba, 2017).

Figura 1 - Representação de um Sistema Regional de Inovação

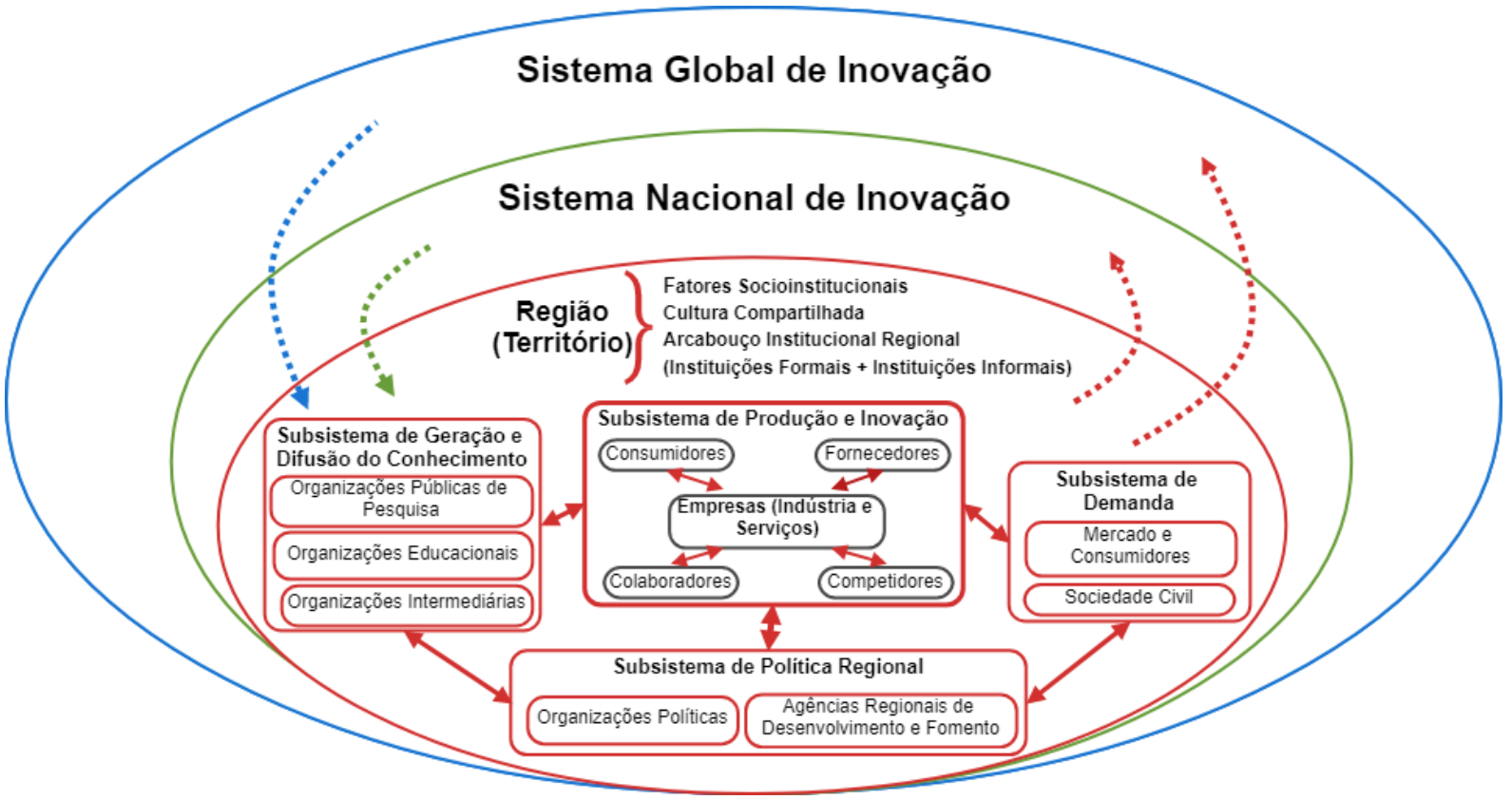

Fonte: Elaboração própria com base em Tödtling e Trippl (2005).

Paralelamente, é importante levar em conta que o Sistema Regional de Inovação também tem uma forte interface com o território. Fatores como a cultura compartilhada e o arcabouço institucional específico, formado pela conjugação de instituições formais e informais, contribuem para conferir essa especificidade. A “densidade institucional” da região 
é crítica para que a cooperação, o aprendizado e os fluxos de conhecimento aconteçam (Gertler, 2010; Storper, 1997).

O framework de Sistemas Regionais de Inovação, portanto, se mostra funcional para compreender as potencialidades e limites para um determinado território construir uma agenda de desenvolvimento baseada na geração e difusão de conhecimento e inovação. A análise da dinâmica interna de cada subsistema, bem como da interação entre os mesmos, apesar de artificial, é útil para fins analíticos e metodológicos. Na seção seguinte vamos detalhar de que maneira operacionalizamos este referencial, e, posteriormente, iremos apresentar os resultados encontrados que servirão de subsídio para a discussão acerca dos possíveis caminhos de desenvolvimentos para o Estado do Rio de Janeiro.

\section{METODOLOGIA}

Em primeiro lugar, foram utilizados artigos científicos publicados em periódicos indexados para fazer uma breve revisão da literatura acerca do conceito de Sistemas Regionais de Inovação. Com base nessa revisão foi proposto o modelo teórico (Figura 1) que serviu de base para a caracterização do SRI fluminense.

Em seguida, com intuito de caracterizar os principais ativos do SRI fluminense, optamos por utilizar o esquema mostrado na Figura 1 como base, analisando separadamente: i) o subsistema de geração e difusão do conhecimento; ii) a interação deste com o subsistema de Produção e Inovação; e, por fim, iii) o subsistema de Produção e Inovação em si. A análise de cada uma destas dimensões foi feita através do levantamento de dados secundários extraídos de publicações e bases de dados das seguintes instituições: MCTI, CNPq, CAPES, CGEE, IBGE (PINTEC e RAIS) associado ao uso de estatística descritiva no tratamento dos dados.

Para analisar o subsistema de geração e difusão do conhecimento optamos, em primeiro lugar, por dar ênfase ao financiamento público das atividades de C,T\&I, pois este tipo de financiamento é o mais relevante no país. Para tanto, utilizamos os dados fornecidos pelo MCTI na publicação “Indicadores Nacionais de Ciência, Tecnologia e Inovação - 2019”. Em seguida, com base nos dados disponíveis na Plataforma Sucupira da CAPES e no Diretório de Grupos de Pesquisa do CNPq (DGP/CNPq) traçamos um panorama dos Grupos de Pesquisa existentes no estado e fizemos uma comparação com outros estados relevantes, a fim de identificar as competências científicas que o ERJ possui e as Bases de Conhecimento do SRI fluminense. Através de uma publicação do CGEE também investigamos a distribuição 
de mestres e doutores titulados por Grande Área de Conhecimento para verificar em quais áreas o estado possui vantagens comparativas.

A interação entre os subsistemas de geração e exploração de conhecimento foi analisada com base na distribuição do emprego de mestres e doutores nos diferentes subsetores econômicos fornecida pela RAIS, bem como pelos dados relativos ao relacionamento entre grupos de pesquisa e empresas, disponibilizados pelo DGP/CNPq. Para complementar a análise, utilizamos artigos e teses recentes para compreender a atuação dos mecanismos de geração de empreendimentos inovadores existentes no estado na promoção da interação entre ambos os subsistemas.

Para investigar o subsistema de Produção e Inovação, utilizamos os dados da Pesquisa de Inovação Tecnológica do IBGE (PINTEC/IBGE), que, apesar de limitados, seguem um modelo reconhecido internacionalmente, possuem regularidade temporal e são comparáveis regionalmente. A partir dos dados disponíveis na PINTEC foi possível examinar as rotinas das empresas, com destaque para a dinâmica inovativa, os dispêndios em inovação, as fontes de informação, relações de cooperação e parcerias.

Por fim, nos baseamos nos dados levantados e em outros trabalhos de nossa autoria em parceria com colaboradores para pensar nos desafios da construção de uma agenda de desenvolvimento pós Covid-19 para o estado do Rio de Janeiro e propor estratégias possíveis e políticas adequadas. A construção desta agenda e a definição das estratégias relacionadas à mesma seriam de responsabilidade do subsistema de política regional (cf. Figura 1).

\section{RESULTADOS}

\subsection{Subsistema de Geração e Difusão do Conhecimento}

Um elemento crucial para o funcionamento do subsistema de geração e difusão do conhecimento em um SRI é o financiamento, sobretudo público, das atividades de Ciência e Tecnologia desenvolvidas no mesmo. A publicação "Indicadores Nacionais de Ciência, Tecnologia e Inovação - 2019”, elaborada pelo Ministério da Ciência, Tecnologia, Inovações e Comunicações (MCTI), detalha a evolução dos dispêndios dos governos estaduais em Ciência e Tecnologia no período 2000-2017. A publicação considera como ciência e tecnologia as atividades de Pesquisa e Desenvolvimento Experimental (P\&D) e Atividades Científicas e Técnicas Correlatas (ACTC) ${ }^{3}$.

\footnotetext{
${ }^{3}$ Para mais detalhes ver MCTI (2019).
} 
No caso do Estado do Rio de Janeiro, o Gráfico 1 mostra que entre 2000 e 2015 houve um aumento consistente do dispêndio do governo estadual em C\&T, que passou de R \$250,7 milhões para R \$ 1.477,2 milhões, sofrendo uma pequena queda nos anos seguintes, fechando 2017 com R \$ 1.323,70 milhões investidos. Os dados do MCTI também mostram que em 2017 o dispêndio do governo estadual fluminense em C\&T correspondeu a 1,69\% de suas receitas totais, percentual menor que o de Santa Catarina $(1,7 \%)$, da Paraíba $(2,05 \%)$, Paraná $(2,16 \%)$ e São Paulo (5,1\%). O percentual médio de investimento estadual em C\&T entre 2000 e 2017 no ERJ foi de 1,3\%, sendo menor que o dos estados da Bahia (1,41\%), Santa Catarina $(1,49 \%)$, Paraná $(2,4 \%)$ e São Paulo $(4,35 \%)$.

Outra agência federal que possui grande importância na concessão de bolsas de mestrado e doutorado é o CNPq, que em 2018 concedeu 16.962 bolsas desse tipo no Brasil, sendo 2.748 - aproximadamente $21 \%$ - no Estado do Rio de Janeiro. Apenas o Estado de São Paulo teve mais bolsas concedidas pela agência: 5.812. A FAPERJ, por seu turno, concedeu 1.343 bolsas de mestrado e doutorado em 2018, o que corresponde a aproximadamente $22 \%$ das 6.227 bolsas que a instituição distribuiu no mesmo ano.

Gráfico 1- Dispêndio do Governo Estadual do Rio de Janeiro em Ciência e Tecnologia (C\&T) entre 2000 e 2017 em milhões de R $\$$ correntes

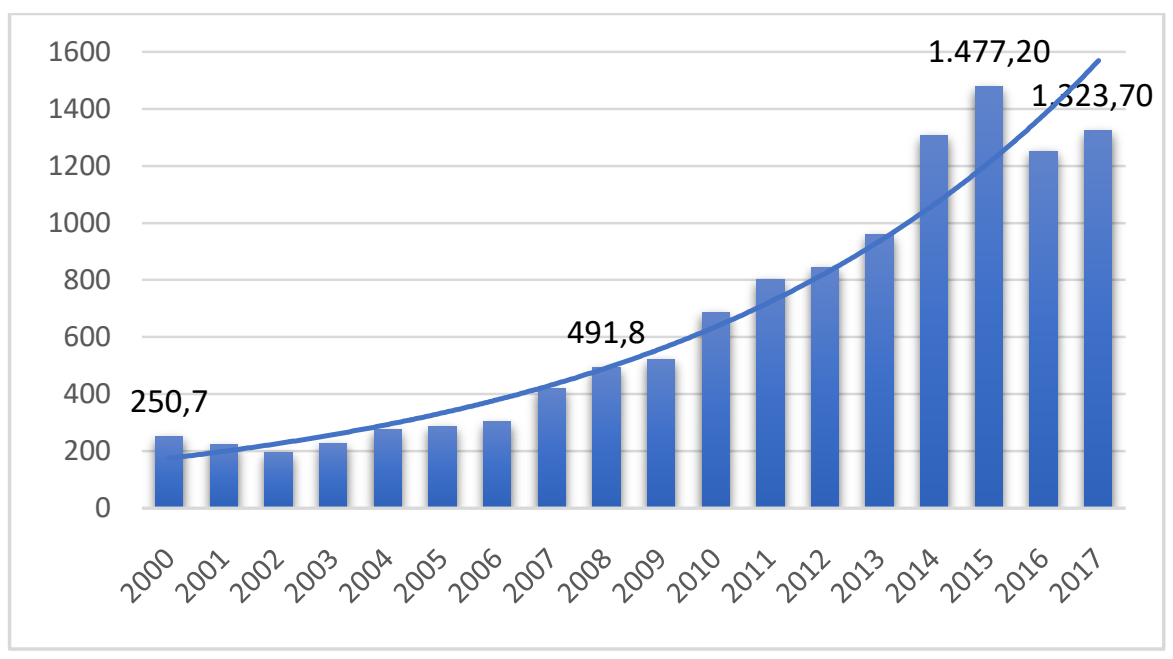

Fonte: Elaboração própria com base em MCTI (2019)

Os recursos disponibilizados para ciência e tecnologia no estado em sua maioria são canalizados para os diversos Grupos de Pesquisa (GP) localizados nas ICTs fluminenses. É relevante, portanto, mapear os grupos de pesquisa existentes no estado, bem como as áreas em que atuam, com objetivo de traçar um panorama da infraestrutura local de geração de conhecimento. Nosso mapeamento indicou um predomínio de GP em Ciências Humanas 
(939) e Ciências Sociais Aplicadas (721) no ERJ, ao passo que Ciências Agrárias (139) e Linguística, Letras e Artes (301) são as áreas com menos grupos de pesquisa registrados. No nível intermediário destacam-se as seguintes áreas: Ciências da Saúde (658), Engenharias e Computação (583), Ciências Biológicas (567) e Ciências Exatas e da Terra (442). Entretanto, isoladamente estes números nos dizem pouca coisa. Para obter uma melhor compreensão deste quadro é preciso comparar esses valores ao total do país. Neste prisma, o Gráfico 2 detalha o peso relativo do total de GPs em cada Grande Área de Conhecimento no Brasil, Rio de Janeiro e outros estados selecionados ${ }^{4}$.

Gráfico 2 - Distribuição (\%) do número de Grupos de Pesquisa no Brasil, Rio de Janeiro, São Paulo, Minas Gerais e Rio Grande do Sul por Grande Área do Conhecimento, 2016

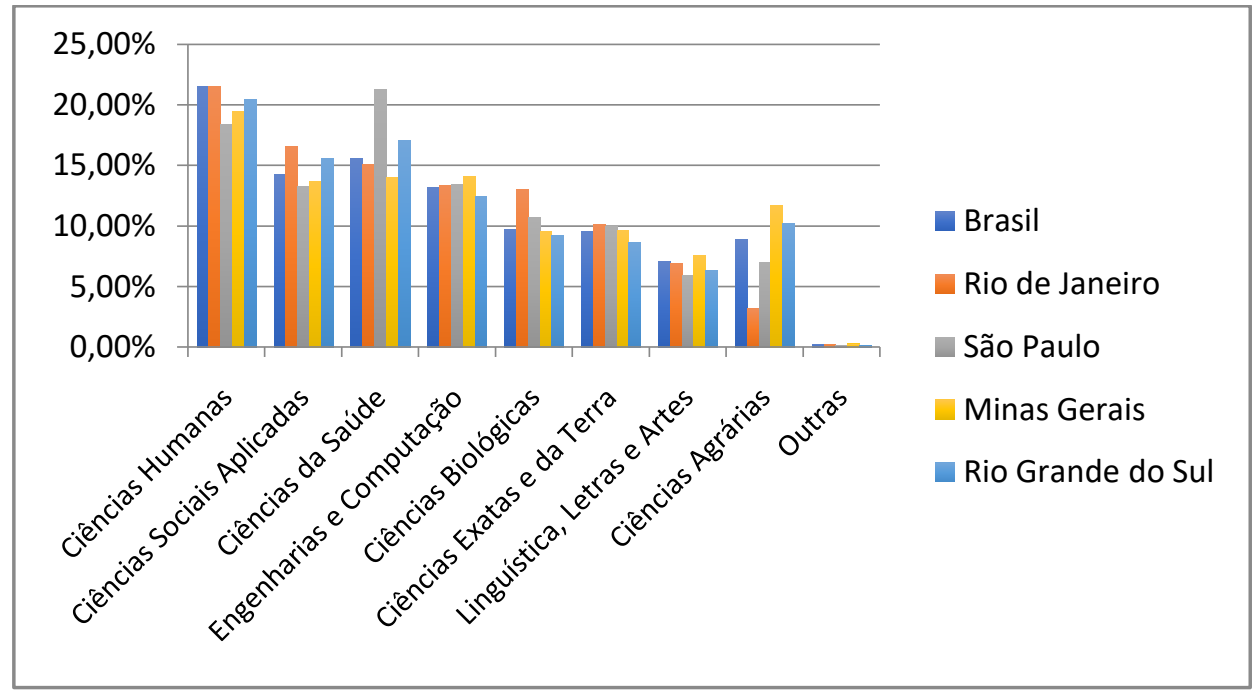

Fonte: DGP/CNPq (2019)

Em relação à média nacional e aos outros estados selecionados, no último levantamento disponível (2016), o Estado do Rio destaca-se nas áreas de Ciências Sociais Aplicadas, que corresponde a 16,54\% do total de GP, Ciências da Saúde (15,09\%), Engenharias e Computação (13,37\%) e Ciências Biológicas (13\%). As três últimas áreas têm grande potencial de relação com o setor produtivo e se beneficiam respectivamente da presença da FIOCRUZ, como foi corroborado na atual crise sanitária decorrente da pandemia do novo coronavírus, e de todo o aparato de pesquisa voltado ao setor de petróleo e gás, bem como da própria Petrobras no território fluminense.

Analisar somente o quantitativo de programas, entretanto, é insuficiente na medida em que este dado não retrata o impacto e a qualidade da pesquisa realizada. Desse modo, para ter

\footnotetext{
${ }^{4}$ Foram selecionados os estados de São Paulo, Minas Gerais e Rio Grande do Sul, pois ao lado do Rio de Janeiro são os que possuem proporcionalmente o maior número de Grupos de Pesquisa no país.
} 
uma visão mais precisa das áreas nas quais o estado possui maior competência de geração de conhecimento identificamos os Programas de Pós-Graduação (PPG) sediados no ERJ com maiores notas na avaliação da CAPES no quadriênio 2013-2016. Optamos por elencar os Programas que atingiram nota 6 e nota 7 na última avaliação com resultados disponíveis. De forma geral, observa-se uma grande diversidade no conjunto de PPGs melhor avaliados, com um bom equilíbrio entre Ciências Humanas, Exatas e Biológicas. Considerando as áreas que possuem maior afinidade e potencial de relação com o setor produtivo salientam-se as Ciências Biológicas, principalmente Bioquímica; as Engenharias, com destaque para Engenharia de Materiais e Metalúrgica, Engenharia Química, Engenharia Mecânica e Engenharia Elétrica; e as áreas de Biotecnologia, Ciência da Computação, Geociências, Medicina e Química.

Além das atividades de pesquisa, os Grupos de Pesquisa e mais especificamente os Programas de Pós-Graduação também auxiliam na formação de mão de obra altamente qualificada nas diferentes áreas de conhecimento. Através dos PPGs todo ano são titulados mestres e doutores que alimentam a infraestrutura de pesquisa, como também são inseridos nas empresas, onde utilizam o conhecimento adquirido para desenvolver tecnologias e inovações.

Assim como ocorreu em todo o Brasil, o Estado do Rio de Janeiro aumentou de forma consistente a titulação de mestres e doutores (Gráfico 3) nos últimos 22 anos a partir de 2017, ano mais recente ao qual o levantamento do CGEE aqui utilizado se refere. Neste período foram concedidos 100.683 títulos de mestrado e 32.719 títulos de doutorado no estado, o que equivale a aproximadamente $13,5 \%$ e $14,2 \%$ do total de títulos de mestrado e de doutorado concedidos no país no período respectivamente. Estes números colocam o Rio de Janeiro como segundo estado com maior concessão de títulos de mestrado e doutorado do país.

Gráfico 3 - Número de Títulos de Mestrado e Doutorado concedidos no Rio de Janeiro, 19962017 


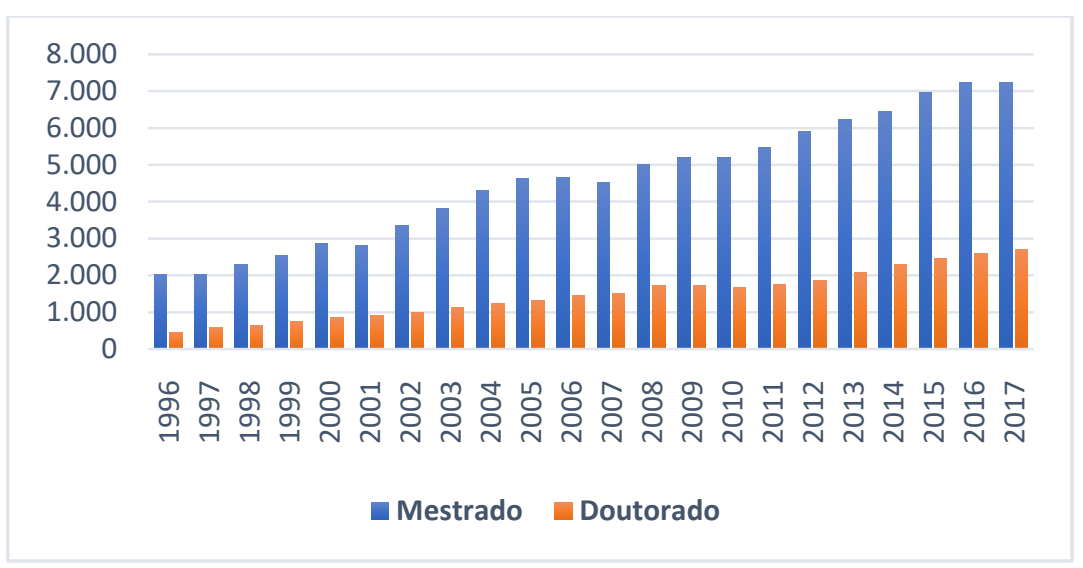

Fonte: CGEE (2019)

Considerando a distribuição da titulação de mestres e doutores por Grande Área de Conhecimento em relação ao país e a outros estados, o ERJ destaca-se praticamente nas mesmas áreas nas quais possui relativamente mais Grupos de Pesquisa e Programas de PósGraduação melhor avaliados. Em relação à formação de mestres, o ERJ sobressai-se relativamente ao país e a outros estados relevantes nas seguintes áreas: Ciências Biológicas, Ciências Exatas e da Terra, Ciências Sociais e Aplicadas e Engenharias. É surpreendente constatar que as Engenharias correspondem a quase $18 \%$ do total de mestres titulados em território fluminense, número bastante superior à média nacional $(12,72 \%)$ e mesmo de estados como São Paulo e Minas Gerais (13,69\% e 13,54\%, respectivamente).

No tocante à titulação de doutores, o Rio de Janeiro também se destaca em Ciências Biológicas, Ciências Exatas e da Terra, Engenharias e Linguística, Letras e Artes. A área de Engenharias se mostra bastante relevante ao ser responsável por quase $16 \%$ do total de títulos de doutorado concedidos no estado, valor largamente superior à média nacional $(11,02 \%)$ e de estados como São Paulo e Minas Gerais (10,29\% e 10,57\%, respectivamente).

Essa performance de destaque na área de Engenharia está relacionada ao significativo aparato de pesquisa ligado à indústria petrolífera (Marcellino et al., 2013), tendo como principais pilares a COPPE - Instituto Alberto Luiz Coimbra de Pós-Graduação e Pesquisa de Engenharia/UFRJ, que tem um histórico bem sucedido de relação com o Centro de Pesquisas da Petrobras (CENPES) - ambos localizados no Fundão; bem como o Tecgraf e o Laboratório de Engenharia de Software, ambos sediados na PUC-RIO e com ampla tradição na relação com o setor produtivo fluminense (Guaranys, 2006). Esta vantagem comparativa na área de Engenharia pode ser um ativo estratégico para o desenvolvimento de inovações em setores 
nos quais predominam a Base de Conhecimento Sintética ${ }^{5}$, tais como construção naval, automobilística e metal-mecânica.

\subsection{Interação entre os Subsistemas de Geração e de Exploração do Conhecimento}

Em um sistema regional de inovação dinâmico, o subsistema de geração de conhecimento deve interagir constantemente e de múltiplas formas com o subsistema de Produção e Inovação. Em linhas gerais, espera-se que os esforços e recursos financeiros e humanos investidos na infraestrutura de pesquisa consigam se inserir e se conectar com o setor produtivo e com o mercado de forma geral.

Uma das formas de interação entre ambas as dimensões, por exemplo, está relacionada à inserção dos mestres e doutores formados pelas Instituições Científico-Tecnológicas (ICTs) no mercado de trabalho. Estes mestres e doutores adquirem conhecimentos e técnicas que podem ser úteis para o desenvolvimento de tecnologias e inovações nas empresas. Ao mesmo tempo, ao se inserir em empresas e organizações da sociedade estes profissionais altamente qualificados contribuem para aumentar a capacidade de absorção destas instituições, bem como para auxiliar na difusão da inovação no tecido produtivo regional.

A análise da evolução da distribuição destes mestres e doutores nos diferentes subsetores ${ }^{6}$ econômicos, portanto, permite apreender de que maneira a economia regional absorve estes profissionais altamente qualificados. Supõe-se que quanto mais complexa a infraestrutura científico-tecnológica e mais diversificada a estrutura produtiva, sobretudo em setores de média e alta tecnologia, maior a probabilidade a região possui em gerar postos de trabalho altamente qualificados, e assim empregar mestres e doutores. Simultaneamente, quanto mais mestres e doutores inseridos em empresas, sobretudo exercendo atividades de Pesquisa, Desenvolvimento e Inovação, maior a capacidade de absorção e de inovação, e, consequentemente, a competitividade destas firmas.

\footnotetext{
${ }^{5}$ A Base de Conhecimento Sintética prevalece em indústrias que produzem inovações por meio do uso e de novas combinações de conhecimento existente. Isto ocorre principalmente quando problemas específicos que surgem na relação entre clientes e fornecedores precisam ser solucionados. Os exemplos mencionados na literatura são: engenharia industrial, equipamentos industriais avançados e construção naval, onde produtos são criados geralmente em pequenas séries (Asheim e Gertler, 2005).

${ }^{6}$ Consideramos aqui os 25 subsetores definidos pela CNAE/IBGE, sendo eles: Indústria Extrativa Mineral; Produção de Mineral Não Metálico; Indústria Metalúrgica; Indústria Mecânica; Elétrico e Comunicação; Material de Transporte; Madeira e Mobiliário; Papel e Gráfica; Borracha, Fumo e Couros; Indústria Química, Indústria Têxtil; Indústria de Calçados; Alimentos e Bebidas; Serviços de Utilidade Pública; Construção Civil; Comércio Varejista; Comércio Atacadista; Instituição Financeira; Administração Técnica Profissional; Transporte e Comunicações; Alojamento e Comunicação; Médicos, Odontológicos, Veterinários; Ensino; Administração Pública; e Agricultura.
} 
Em relação à evolução da participação de cada subsetor no emprego de mestres no Estado do Rio de Janeiro entre 2006 e 2019, nota-se o forte predomínio de dois subsetores em particular: Ensino e Administração Pública. Em 2019, último ano com dados disponíveis, a combinação dos dois setores representava 75,6\% do emprego de mestres no ERJ, ou seja, mais de 3 em cada 4 trabalhadores com mestrado no estado estava inserido em instituições públicas ou voltadas para atividades de Ensino - geralmente Instituições de Ensino Superior. Cabe ressaltar que a participação do subsetor Administração Pública saltou de 2,1\% em 2006 para 44,3\% em 2019, enquanto a participação do subsetor Ensino diminuiu de 55,2\% para $31,3 \%$ no mesmo intervalo.

Apesar da possibilidade dos profissionais empregados nos subsetores de Ensino (Instituições de Ensino Superior) e Administração Pública (Instituições CientíficoTecnológicas Públicas) estarem envolvidos com atividades de Pesquisa, Desenvolvimento e Inovação, é bastante provável que estas atividades se concentrem nas fases iniciais de desenvolvimento tecnológico, sobretudo, pesquisa básica e pesquisa experimental. A inovação só ocorre quando uma invenção ou tecnologia são introduzidas no mercado, sendo, portanto, a empresa o lócus privilegiado do processo inovativo. Neste sentido, a inserção de mestres e doutores no setor produtivo, em última instância nas empresas, é crucial para ampliar a capacidade de inovação do sistema de inovação regional.

No que diz respeito à dinâmica da participação dos subsetores no emprego de doutores no Estado do Rio de Janeiro no mesmo período verifica-se um padrão semelhante. No entanto, neste caso há uma ampla predominância da participação do subsetor Ensino, que se manteve quase sempre superior a 50\% nos anos selecionados e chegou a 63,8\% em 2019. A soma da participação deste subsetor, com a participação dos subsetores Administração Pública e Administração Técnica Profissional corresponde a 88,9\% do emprego de doutores no ERJ em 2017. i. e., quase 9 em cada 10 doutores empregados formalmente.

Estes dados indicam uma fragilidade na interação entre os subsistemas de geração e exploração de conhecimento do SRI fluminense, bem como na capacidade de absorção do mesmo. Ao longo do tempo, esta fragilidade se acentuou, refletindo-se em pouca diversidade setorial e alta concentração de mestres e doutores em atividades de Ensino e na Administração Pública. Esta dificuldade do setor produtivo regional em absorver mão de obra altamente qualificada representa um obstáculo para a dinâmica inovativa local.

Outra forma de interação entre a infraestrutura científico-tecnológica e o setor produtivo se estabelece por meio da relação entre Grupos de Pesquisa e Empresas. Através do 
Diretório de Grupos de Pesquisa do CNPq (DGP/CNPq) é possível identificar o total de GP que relataram relação com empresas em cada estado desde 2002. Entre 2002 e 2016 - último ano com dados disponíveis -, houve simultaneamente no ERJ um aumento do total de Grupos de Pesquisa, bem como do número de Grupos que relataram relacionamento com empresas (ver Gráfico 4). Em 2016, dos 4.360 grupos existentes no Rio de Janeiro, 1.645 relataram relacionamento com empresas.

Gráfico 4 - Total de Grupos de Pesquisa e Número de Grupos de Pesquisa que Relataram Relacionamentos com Empresas no Estado do Rio de Janeiro nos anos de 2002, 2004, 2006, 2008 , 2010, 2014, 2016

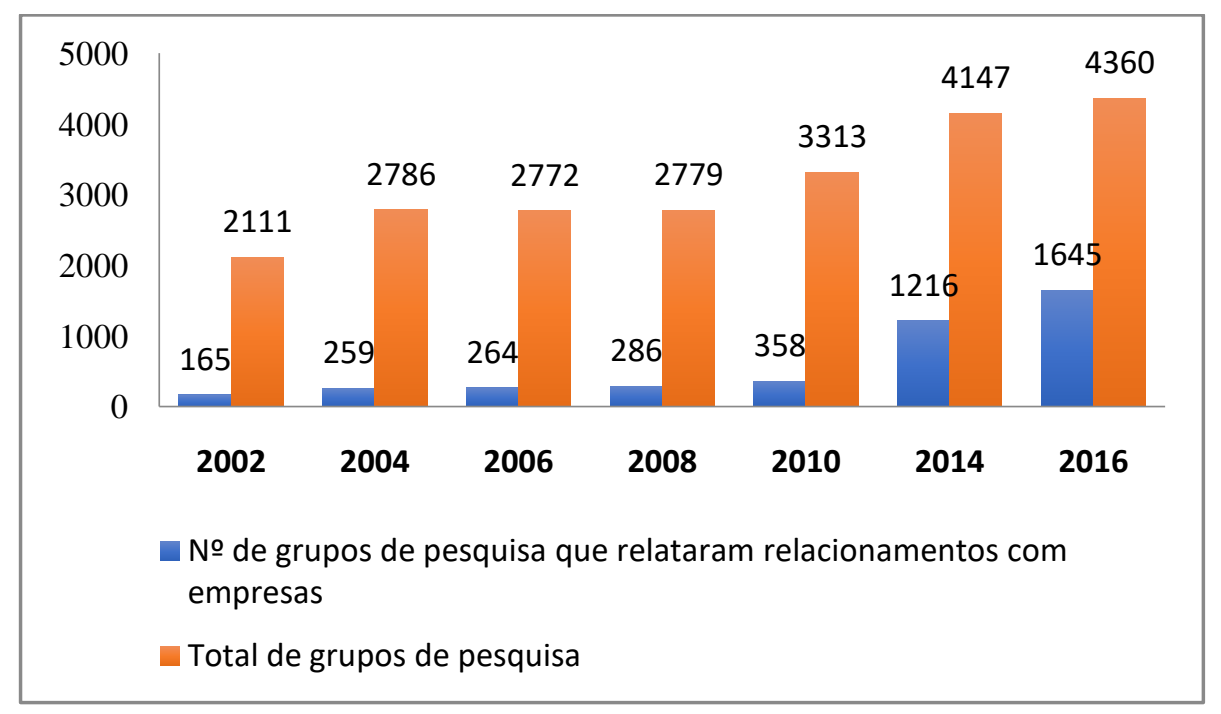

Fonte: DGP/CNPq

Considerando a evolução do percentual de Grupos de Pesquisa que relataram relacionamentos com empresas no ERJ no mesmo período, houve um aumento significativo: enquanto no ano de 2002 apenas 7,82\% dos GP fluminenses relataram relacionamento com empresas, em 2016 este número chegou a 37,73\%. Este salto ocorreu entre 2010 e 2014, quando houve um aumento de $10,81 \%$ para $29,32 \%$, consolidando-se dois anos depois quando atingiu quase $38 \%$. Esta evolução fez com que o Rio de Janeiro passasse do $17^{\circ}$ para o $2^{\circ}$ lugar entre os estados do país com maiores taxas de relacionamento entre Grupos de Pesquisa e Empresas.

Algumas hipóteses podem ser levantadas acerca do aumento expressivo do percentual de relacionamento de Grupos de Pesquisa com Empresas desde 2010. Um dos principais fatores que pode explicar esta ascensão expressiva da taxa de relacionamento é a descoberta do Pré-Sal em 2007, que trouxe uma multiplicidade de desafios científicos e tecnológicos relativos à sua exploração. A grande expertise em pesquisas relacionadas ao setor de $\mathrm{P} \& \mathrm{G}$, a 
presença do centro de pesquisas da Petrobras no campus da Ilha do Fundão - UFRJ, a instalação de centros de P\&D de multinacionais, a entrada de novos players do setor no mercado e a obrigação de investimento em P\&D regulamentada pela lei $n^{\circ}$ 9.991/2000 impulsionaram a realização de pesquisas e a interação entre ICTs e empresas em diferentes áreas do conhecimento (Marcellino 2014).

Outro elemento que pode ter contribuído para explicar este aumento na interação entre GP e Empresas é a designação do Complexo Econômico-Industrial da Saúde (Gadelha et al., 2017) como um dos setores prioritários no Plano Brasil Maior, lançado em 2011 (Metten et al., 2015). Com objetivo de fortalecer a capacidade produtiva e de geração e difusão do progresso técnico do complexo da saúde no país, o Plano previa, entre outras coisas, desenvolver o parque produtivo de fármacos, medicamentos, equipamentos e materiais de uso em saúde no país; e utilizar o poder de compra governamental para aquisição de produtos e serviços estratégicos para o Sistema Único de Saúde (SUS). Deste modo, em virtude da presença da FIOCRUZ e de uma série de Grupos de Pesquisa de ponta nas áreas de Ciências Biológicas e Ciências da Saúde, o Estado do Rio de Janeiro estava em posição estratégica para subsidiar as empresas nacionais a atingir os objetivos previstos no plano.

Em um plano mais geral, a expansão e consolidação de instrumentos de apoio à inovação de agências de fomento federais e regionais que estimulam e demandam a interação entre ICTs e Empresas nos últimos quinze anos também podem estar por trás deste avanço na taxa de relacionamento no estado. O fato é que o ERJ abriga uma infraestrutura de ciência e tecnologia expressiva e qualificada, bem como possui tradição na relação entre esta infraestrutura e o setor produtivo em alguns setores, tais como Petróleo e Gás e Farmacêutico. No entanto, as evidências apontam que a interação entre os subsistemas de geração e aplicação do conhecimento ainda é precária, e, consequentemente, dificulta a transformação do conhecimento em tecnologias e inovações, bem como minimiza a capacidade de absorção das empresas de todos os portes do sistema de inovação regional.

Neste contexto, os mecanismos de geração de empreendimentos inovadores, incluindo incubadoras, aceleradoras e parques tecnológicos, podem atuar como "instituições-ponte" (Sapsed et al., 2007) e contribuir para a interação entre a infraestrutura de ciência e tecnologia e o setor produtivo. Tais mecanismos podem ter um impacto significativo na região em que estão inseridos, estabelecer pontes entre diferentes atores locais e externos e, consequentemente, alavancar a difusão de conhecimento e o estímulo a processos de aprendizado e inovação. Entretanto, a atuação das incubadoras enquanto "instituições-ponte" 
na difusão do conhecimento dependerá em grande medida do ambiente institucional no qual elas estão inseridas (Santos, 2016; 2020a).

O ERJ possui uma série de instituições desta natureza (Santos, 2016; da Hora, 2019), no entanto, a simples existência destes mecanismos não é garantia de interação entre a infraestrutura de ciência e tecnologia e o setor produtivo. Santos (2016) observou que a relação das incubadoras fluminenses com a infraestrutura de $C, T \& I$ se restringia, na maior parte dos casos, à utilização do espaço físico e ao acesso à mão de obra qualificada. No que diz respeito ao alinhamento com o setor produtivo, as incubadoras metropolitanas apresentavam aderência limitada, buscando na maior parte dos casos atender demandas nacionais e globais, ao passo que as incubadoras localizadas no interior, apesar de terem como objetivo atender demandas regionais e locais, encontravam obstáculos como baixo nível de empreendedorismo, alto grau de informalidade do mercado de trabalho, pouca qualificação de sua mão de obra e predomínio de atividades econômicas com baixo valor agregado (Santos, 2016; 2020a).

De maneira similar, da Hora (2019) em trabalho sobre os Parques Científicos, Tecnológicos e de Inovação tanto em fase de construção, projeto e implantação, quanto em fase de operação no Estado do Rio de Janeiro concluiu que:

Entre os parques em operação, observa-se que, ainda que a média de tempo de existência seja 22 anos, (...) isso não se traduz efetivamente em processos de atração e retenção de organizações para os parques, com o estabelecimento de parcerias, desenvolvimento de produtos, serviços e patentes, entre outros resultados (Hora, 2019, p. 177, grifo nosso).

Considerando a interação entre os diferentes atores, o autor salienta que somente o Parque Tecnológico da UFRJ apresenta interação mútua entre as três hélices, ao passo que nos demais parques analisados "é percebida a presença dos três elementos, mas sem a intercalação da atuação destes, ou de proximidade conjunta das hélices entre si” (da Hora, 2019). O autor finaliza argumentando que nos parques analisados:

relações sensíveis e restritas entre a hélice empresarial e a governamental, e entre esta e a acadêmica, indicam dificuldades em fazer "girar" o mecanismo, que produz inovação e desenvolvimento. Nesse sentido, as relações precisam ser aprimoradas, principalmente no que tange à relação com do poder público com os demais atores e da academia com o meio produtivo (da Hora, 2019, p. 180, grifos nossos). 
Esta limitação na relação entre a infraestrutura de ciência e tecnologia e o setor produtivo pode impactar negativamente a geração, aplicação e difusão de conhecimento em nível regional. Na próxima seção, portanto, iremos analisar a dinâmica do subsistema de Produção e Inovação do SRI fluminense tendo como foco as empresas, que são os principais agentes do processo de inovação.

\subsection{Subsistema de Produção e Inovação}

Para analisar a evolução da dinâmica inovativa das empresas no Estado do Rio de Janeiro e compará-la com a de outros estados do país optamos por utilizar os dados da Pesquisa de Inovação Tecnológica (PINTEC), realizada a cada três anos pelo IBGE. A pesquisa tem como objetivo construir indicadores setoriais, nacionais e regionais das atividades de inovação tecnológica nas empresas industriais brasileiras, do setor de eletricidade e gás e de serviços selecionados (arquitetura, engenharia, testes e análises técnicas, edição, telecomunicações e informática e pesquisa e desenvolvimento) ${ }^{7}$, compatíveis com as recomendações internacionais em termos conceituais e metodológicos.

Além das restrições setoriais, a PINTEC considera apenas empresas com dez ou mais empregados. Ademais, a distribuição da amostra é feita de modo que $80 \%$ das empresas da amostra são originárias dos estratos das potenciais inovadoras e $20 \%$ dos estratos sem indicação de potencial inovador (IBGE, 2020). O caráter amostral faz com que os resultados de cada unidade federativa possam estar enviesados devido às especificidades do desenho da amostra $^{8}$. A despeito das limitações apontadas, a pesquisa oferece um bom retrato da dinâmica e da estratégia inovativa das empresas nacionais, bem como auxilia na identificação de padrões de inovação em âmbito regional.

\subsubsection{Dinâmica Inovativa}

A fim de ter uma visão mais apurada do desempenho do Rio de Janeiro, selecionamos quatro estados para servirem de comparação, considerando o porte da economia (São Paulo e

\footnotetext{
${ }^{7}$ A PINTEC inclui somente empresas com atividade principal compreendida i) nas seções B e C (Indústrias Extrativas e Indústrias de Transformação, respectivamente); D (Eletricidade e Gás); ii) nas divisões de serviços 61 (Telecomunicações), 62 (Tecnologia da Informação), 71 (Arquitetura, Engenharia, Testes e Análises Técnicas) e 72 (Pesquisa e Desenvolvimento) e no grupo de serviços 63.1 (Tratamento de Dados, Hospedagem na Internet e Outras Atividades Relacionadas); e iii) na combinação de divisão e grupo de serviços 58+59.2 (Edição e Gravação de Som, e Edição de Música) (IBGE, 2020).

${ }^{8}$ Em relação ao Estado do Rio de Janeiro, a amostra e as tendências que indicam são reflexo do alto peso relativo das atividades relacionadas ao complexo de petróleo e gás (Marcellino e Santos, 2017).
} 
Minas Gerais), a semelhança da estrutura produtiva (Rio Grande do Sul), e os resultados positivos recentes em inovação (Santa Catarina). Além da dinâmica inovativa, analisamos também o padrão de dispêndios, as fontes de informação, as relações de cooperação e as parcerias estabelecidas.

Analisando a evolução da taxa de inovação, ou seja, o percentual de empresas que implementaram inovações de produto ou de processo (Gráfico 5), observa-se que o Rio de Janeiro tem se posicionado sistematicamente abaixo dos outros estados selecionados, atingindo o ponto mais baixo no último levantamento, com $24,62 \%$.

Gráfico 5 - Percentual (\%) das empresas das indústrias extrativa e de transformação que implementaram inovações de produto e processo no Rio de Janeiro e em estados selecionados nos períodos 2006-2008, 2009-2011, 2012-2014 e 2015-2017

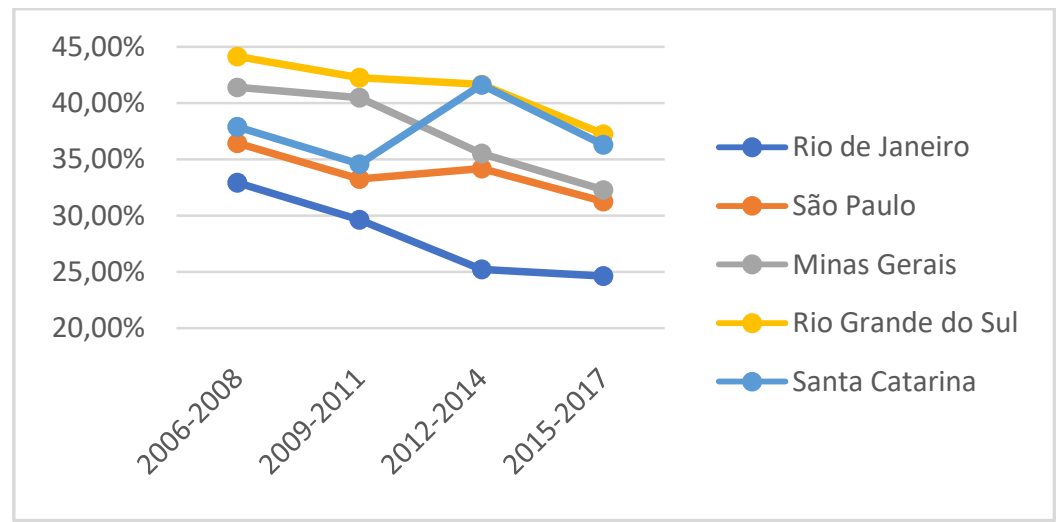

Fonte: PINTEC/IBGE (2020)

Este indicador visto de forma isolada não configura necessariamente uma baixa dinâmica inovativa, uma vez que a mesma pode estar concentrada em poucas empresas de porte elevado (Marcellino e Santos, 2017), como sugerem os outros dados. Ademais, se levarmos em conta as empresas que implementaram apenas inovações organizacionais ou de marketing (Gráfico 6), percebemos que o desempenho fluminense se mantém acima da média nas três últimas pesquisas. Tais inovações possuem menor impacto e estão mais associadas ao setor de serviços, sobretudo àqueles prestados às empresas, tais como consultorias e agências de comunicação.

Gráfico 6 - Percentual (\%) das empresas das indústrias extrativa e de transformação que implementaram apenas inovações organizacionais e/ou de marketing no Rio de Janeiro e em estados selecionados nos períodos 2006-2008, 2009-2011, 2012-2014 e 2015-2017 


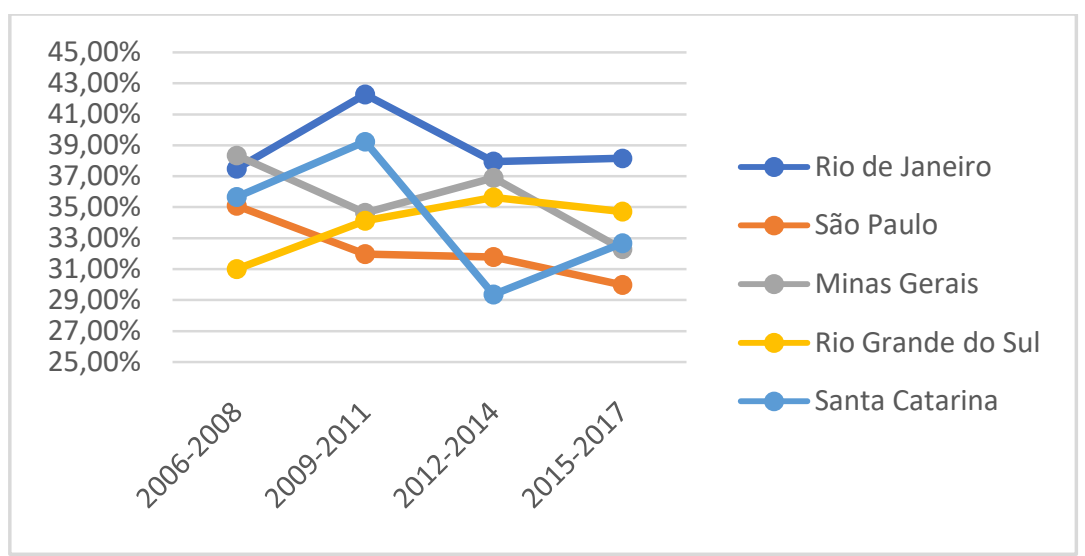

Fonte: PINTEC/IBGE (2020)

São as inovações de produto, entretanto, que possuem maior impacto. Como salientam Britto et al. (2015), estas inovações tendem, mesmo que não obrigatoriamente, a carregar consigo rebatimentos virtuosos para a dinâmica inovativa geral pelo fato de frequentemente acarretarem outras inovações de produto e de processo a ela associadas (Marcellino e Santos, 2017). Analisando a evolução do percentual de empresas que implementaram inovações de produto novas para o mercado nacional (Gráfico 7), nota-se que o Estado do Rio de Janeiro teve uma evolução significativa nos últimos levantamentos, superando todos os demais estados selecionados na PINTEC de 2017.

Gráfico 7 - Percentual (\%) das empresas das indústrias extrativa e de transformação que implementaram inovações de produto novas para o marcado nacional no Rio de Janeiro e em estados selecionados nos períodos 2006-2008, 2009-2011, 2012-2014 e 2015-2017

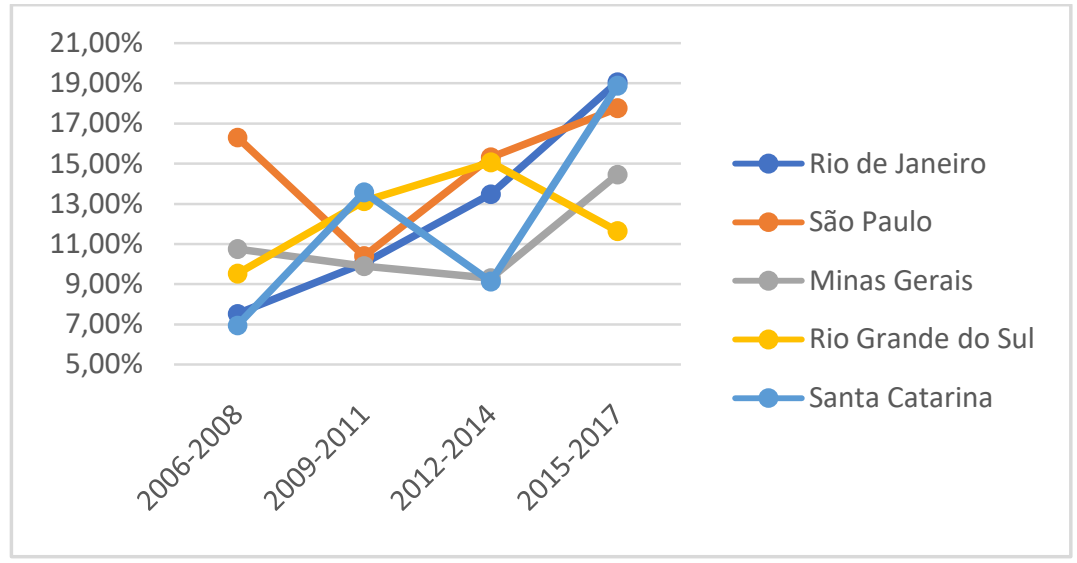

Fonte: PINTEC/IBGE (2020) 
Porém, ao examinar o percentual de empresas que realizaram atividades inovativas ${ }^{9}$ (Gráfico 8), observa-se que o Rio de Janeiro se mantém significativamente abaixo dos outros estados, atingindo somente $19,85 \%$ no triênio 2015-2017.

Gráfico 8 - Percentual (\%) das empresas das indústrias extrativa e de transformação que realizaram Atividades Inovativas no Rio de Janeiro e em estados selecionados nos períodos

2006-2008, 2009-2011, 2012-2014 e 2015-2017

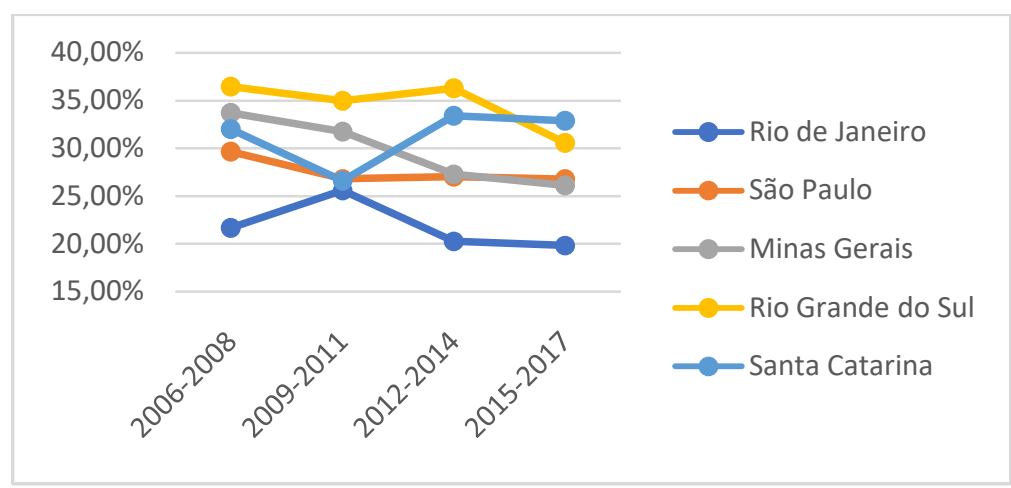

Fonte: PINTEC/IBGE (2020)

\subsubsection{Dispêndios em Inovação}

Ao verificar o percentual dos dispêndios em Atividades Inovativas em relação à Receita Líquida de Vendas (Gráfico 9), constata-se uma queda generalizada nos estados analisados e que o ERJ posiciona-se regularmente abaixo da média dos outros estados. Por outro lado, se levarmos em consideração apenas os dispêndios realizados em atividades internas de P\&D (Gráfico 10) o desempenho fluminense é superior aos dos outros estados, atingindo o auge em 2011, com 1,16\% e se mantendo próximo a 0,7\% no último levantamento.

\footnotetext{
9 Além das Atividades internas de P\&D, incluem também: Aquisição externa de P\&D; Aquisição de outros conhecimentos externos; Aquisição de software; Aquisição de máquinas e equipamentos; Treinamento; Introdução das inovações tecnológicas no mercado; Projeto industrial e outras preparações técnicas para a produção e distribuição. (PINTEC, 2016, pp. 19-20).
} 
Gráfico 9 - Percentual (\%) dos dispêndios realizados em Atividades Inovativas em relação à Receita Líquida de Vendas das empresas no Rio de Janeiro e em estados selecionados nos períodos 2006-2008, 2009-2011, 2012-2014 e 2015-2017

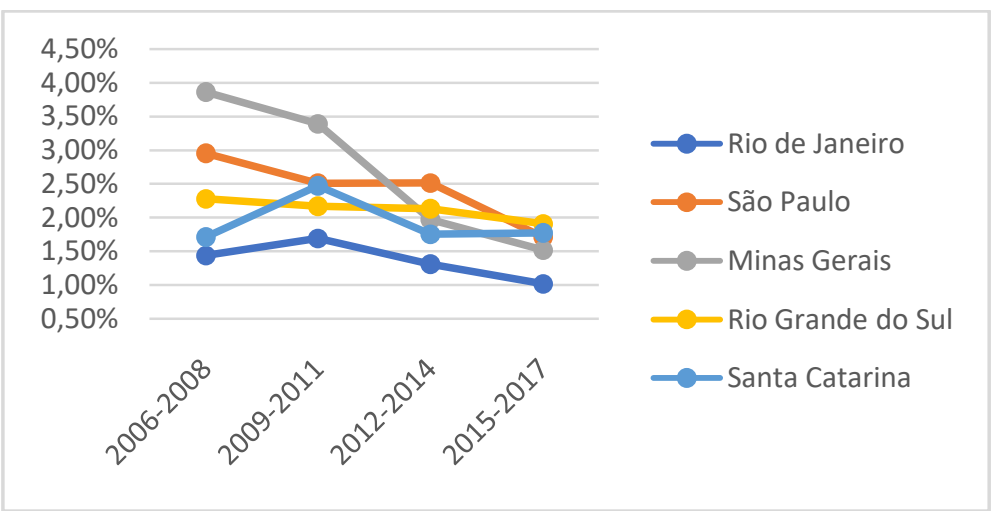

Fonte: PINTEC/IBGE (2020)

Gráfico 10 - Percentual (\%) dos dispêndios realizados em Atividades Internas de P\&D em relação à Receita Líquida de Vendas das empresas no Rio de Janeiro e em estados selecionados nos períodos 2006-2008, 2009-2011, 2012-2014 e 2015-2017

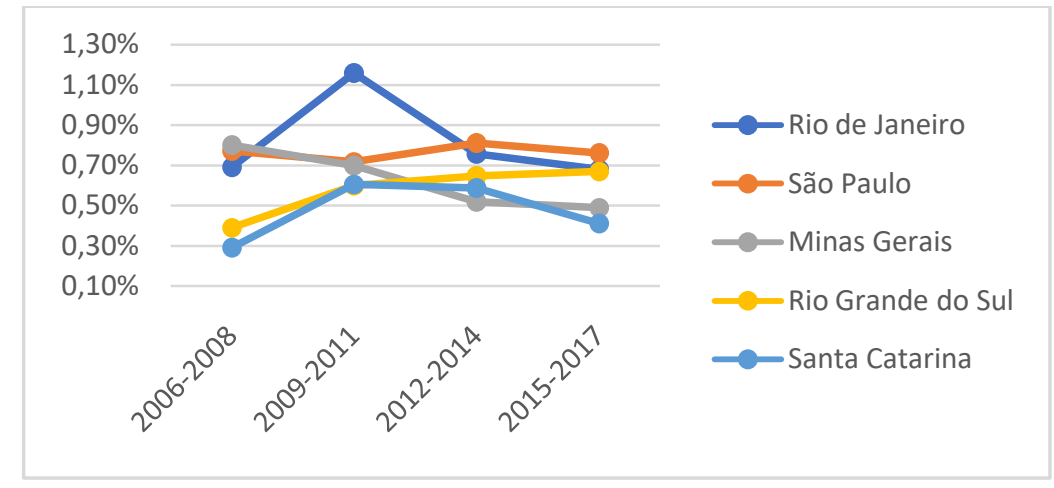

Fonte: PINTEC/IBGE (2020)

Esta aparente dicotomia pode ser explicada pelo fato que as empresas fluminenses privilegiam gastos com $\mathrm{P} \& \mathrm{D}$ interno em detrimento de outros gastos com inovação, o que pode ser visualizado no Gráfico 11.

É interessante notar que apesar do padrão de gastos apontar para um predomínio das atividades internas e externas de $\mathrm{P} \& \mathrm{D}$, as atividades inovativas percebidas como mais importantes pelas empresas do ERJ no triênio 2015-2017 foram: aquisição de máquinas e equipamentos; treinamento; e introdução das inovações tecnológicas no mercado. Em relação 
às atividades internas de $\mathrm{P} \& \mathrm{D}$, somente $11,54 \%$ das empresas consideraram esta modalidade como de alta importância, valor menor que em São Paulo e no Rio Grande do Sul.

Estes dados reforçam a percepção de que no Rio de Janeiro há uma forte concentração de gastos em P\&D em algumas grandes empresas, ao passo que a maioria das empresas inovadoras não realiza gastos formais em $\mathrm{P} \& \mathrm{D}$, com maior foco na aquisição de máquinas e equipamentos, indicando um perfil modernizador. As evidências sugerem ainda que os esforços inovativos se encontram relativamente pouco difundidos entre as empresas que conformam a estrutura produtiva do Estado do Rio de Janeiro, reforçando a hipótese de que há dificuldades para se acelerar o processo de capacitação tecnológica do conjunto da indústria fluminense (Santos e La Rovere, 2017). De acordo com Britto et al. (2015), o ERJ possui uma estrutura industrial que possui simultaneamente elevados esforços em P\&D (conduzidos, sobretudo, por empresas de grande porte), e uma baixa densidade em termos de firmas inovadoras.

Gráfico 11 - Perfil do Gasto em Atividades Inovativas no Estado do Rio de Janeiro, 20122014 e $2015-2017$

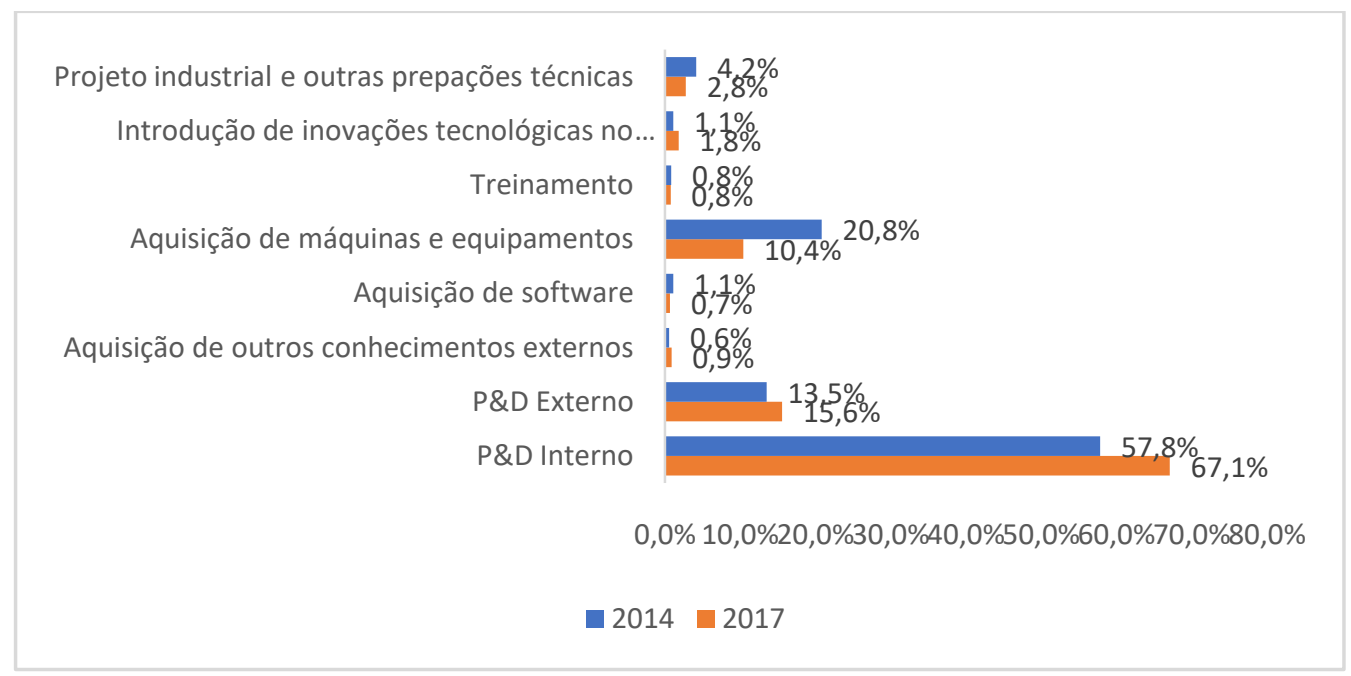

Fonte: PINTEC/IBGE (2020)

De acordo com Marcellino e Santos (2017), as principais características estruturais do sistema de inovação fluminense, em termos de seus padrões de dinâmica inovativa, podem ser sintetizadas nos seguintes pontos: i) setores mais importantes são os vinculados ao complexo de petróleo e gás natural; ii) baixa taxa de inovação; iii) evidências de baixos níveis de difusão; iv) peso relativamente alto das atividades de P\&D; v) dualidade entre a ilha dinâmica 
do complexo de petróleo e gás natural e os demais segmentos de atividade econômica com perfil modernizador.

\subsubsection{Fontes de informação, relações de cooperação e parcerias}

As redes de conhecimento e de inovação não são aleatórias, mas enviesadas, i. e., algumas organizações possuem mais conexões que outras. Além disso, os diferentes tipos de proximidade - geográfica, organizacional, institucional, social e cognitiva - (Boschma, 2005) influenciam, e por vezes determinam, a formação e evolução das redes nas regiões. Cabe ressaltar ainda que dentro dessas regiões as redes não são pervasivas e algumas firmas por vezes agem como brokers, estabelecendo a maioria de suas relações com firmas localizadas em outros territórios.

A partir da PINTEC é possível investigar os padrões de cooperação estabelecidos pelas empresas inovadoras nos estados, e, consequentemente, inferir alguns pontos sobre a estrutura e as características das redes de inovação regionais. Considerando as fontes de informação internas e externas consideradas como de alta importância pelas empresas inovadoras no triênio 2015-2017 nota-se que 28,64\% das empresas consideraram o Departamento de P\&D da própria empresa como fonte de alta relevância, percentual bem superior aos dos outros estados, que variou entre 9,21\% (caso de Santa Catarina) a 14,26\% (caso de São Paulo). Além disso, 7,22\% das empresas fluminenses neste mesmo triênio consideraram como fonte de informação de alta relevância outra empresa do grupo, percentual bem superior ao dos demais estados selecionados.

A significativa representatividade dos Departamentos internos de P\&D corrobora os resultados anteriores e reforça a percepção de que o padrão de inovação da economia fluminense está calcado em grandes empresas que são capazes de investir em pesquisa e desenvolvimento por conta própria. Ao mesmo tempo, o destaque da categoria "Outra Empresa do Grupo" indica que as empresas inovadoras fluminenses fazem parte de grupos econômicos compostos por empresas de diferentes localidades, e que, em alguns casos, a principal fonte de inovação do grupo não está no ERJ. A importância das Universidades e Centros de pesquisa, por um lado, demonstra a relevância da infraestrutura científicotecnológica do estado, e por outro, reforça a visão de que a inovação está concentrada em algumas poucas empresas com capacidade de absorção e de interação sistemática com ICTs. 
Em relação às relações de cooperação estabelecidas pelas empresas inovadoras nos períodos 2012-2014 e 2015-2017, observa-se que, no Rio de Janeiro a taxa de empresas que inovaram com relações de cooperação subiu de 17,11\% em 2014 para 18,16\% em 2017, ficando atrás apenas do Rio Grande do Sul (20,87\%).

No que se refere aos parceiros considerados de alta importância pelas empresas inovadoras no período 2015-2017, 4,85\% das empresas fluminenses consideraram como sendo de alta importância os concorrentes, percentual superior ao dos demais estados, que variou entre 0,16\% (Minas Gerais) e 2,29\% (São Paulo). Além disso, 6,12\% das empresas consideraram a parceria com universidades e institutos de pesquisa como sendo de alta importância, percentual que representa quase o dobro do percentual de São Paulo $(3,23 \%)$ e muito superior ao percentual de Santa Catarina (0,39\%). O peso dos concorrentes pode estar relacionado à presença das empresas inovadoras em cadeias produtivas de escopo nacional e internacional, a exemplo dos setores de $\mathrm{P} \& \mathrm{G}$, energia elétrica e automotivo; enquanto a importância das Universidades e Institutos de Pesquisa pode estar associada ao estrato da amostra dedicado às atividades de $\mathrm{P} \& \mathrm{D}$ e ao parque científico-tecnológico sediado no estado.

Podemos ter maior clareza do cenário ao observar a localização do parceiro das empresas inovadoras que cooperaram no triênio 2015-2017. As empresas fluminenses cooperam mais com fornecedores, empresas de consultoria e outras empresas do grupo localizadas no exterior do que a média dos outros estados selecionados. Além disso, novamente destacam-se as relações com os concorrentes e com as universidades e institutos de pesquisa nacionais.

Grosso modo, estes dados convergem com a hipótese de que o SRI fluminense tem uma carência de cadeias produtivas centradas regionalmente. Neste sentido, infere-se que as empresas inovadoras presentes no estado estão inseridas em redes globais, e, muitas vezes restritas aos grupos econômicos que fazem parte. A relevância e recorrência das relações com outras empresas do grupo e da cooperação com parceiros estrangeiros é característica de setores dominados por oligopólios transnacionais. No caso do Rio de Janeiro, estes setores seriam o de Petróleo e Gás, Automobilístico, Siderúrgico, Naval e Farmacêutico, sendo o de P\&G o mais relevante. A pujança das redes de inovação transnacionais lideradas por matrizes controladas por capital estrangeiro presentes nestes setores contrasta com uma dinâmica inovativa regional incipiente, desarticulada e pouco enraizada no território.

A partir da análise deste padrão de estratégias de cooperação das empresas inovadoras localizadas no ERJ, Marcellino e Santos (2017) identificam um desafio e dois efeitos. No 
nível do território, enfatizam o desafio imposto pelo esvaziamento dos núcleos de comando das cadeias produtivas regionais. Como efeitos deste esvaziamento os autores apontam: i) a conformação de uma estrutura na qual as empresas mais dinâmicas em termos inovativos seguem estratégias de escopo nacional ou global, tendo menor probabilidade de se integrar com interesses regionais e de se articular com estratégias de desenvolvimento produtivo e inovativo para o estado no longo prazo; ii) a necessidade de se pensar a política industrial e tecnológica do ERJ sob a ótica do apoio à constituição de grupos empresariais, sobretudo industriais, com capacidade de liderança estratégica em cadeias produtivas articuladas regionalmente.

\section{DISCUSSÃO: OS DESAFIOS PARA O DESENVOLVIMENTO DO ERJ PÓS COVID-19}

A análise realizada mostrou que o SRI fluminense possui uma série de ativos tecnológicos, financeiros e humanos de grande relevância que podem contribuir para o estado superar a atual crise econômica e construir uma agenda de desenvolvimento pós Covid-19 baseada na geração e difusão de inovações e na solução de desafios societais.

O expressivo volume de recursos aplicados por agências de fomento estaduais e federais contribui para a manutenção de Grupos de Pesquisa de excelência (notas 6 e 7 na avaliação da CAPES) nas áreas de Bioquímica, Biotecnologia, Química, Ciência da Computação, Geociências e nas seguintes Engenharias: Materiais e Metalúrgica, Química, Mecânica e Elétrica. No que tange à formação de recursos humanos altamente qualificados (titulação de mestres e doutores), o ERJ registra desempenho acima da média em Ciências Biológicas, Exatas e da Terra, Sociais Aplicadas e Engenharias. Nota-se, portanto, que do lado da oferta de conhecimento (pesquisa e mão de obra qualificada), o SRI fluminense oferece oportunidades de desenvolvimento tecnológico em diferentes rotas tecnológicas e para diferentes setores, com destaque para a biotecnologia, engenharias, tecnologia da informação e geociências (com ênfase na cadeia de $P \& G$ ).

Não obstante, a interação entre a infraestrutura de ciência e tecnologia e o setor produtivo ainda é incipiente, pontual e restrita a alguns setores específicos, a exemplo do setor de Petróleo e Gás, que possui um histórico de articulação consolidado e ancorado em uma grande empresa estatal. Paralelamente, grande parte dos mestres e doutores titulados no estado se mantém afastada do desenvolvimento tecnológico realizado nas empresas, concentrando-se, sobretudo, em atividades de Ensino e Administração Pública; enquanto que 
as instituições de suporte presentes no estado, com destaque para os mecanismos de geração de empreendimentos inovadores como incubadoras e parques tecnológicos, ainda sofrem com restrições institucionais e geográficas, bem como lacunas na articulação entre as múltiplas hélices.

Do ponto de vista da dinâmica inovativa do setor produtivo, observa-se a convivência entre duas realidades paralelas e contraditórias: de um lado há uma "ilha" dinâmica centrada na cadeia de Petróleo e Gás e composta por grandes empresas que realizam atividades de P\&D e cooperam com parceiros em todo o mundo; e, por outro lado, existe um tecido produtivo desintegrado, pouco dinâmico e com baixo nível de inovação, composto, principalmente, por pequenas e médias empresas industriais e de serviços. Neste sentido, a construção de uma agenda de desenvolvimento para o SRI fluminense passa obrigatoriamente pela superação dessa dualidade e pela formulação de estratégias capazes de utilizar o estoque de conhecimento e os ativos existentes a fim de criar redes de inovação ancoradas nos setores dinâmicos e nas grandes empresas inovadoras e estruturar cadeias produtivas regionalmente centradas. Cabe ressaltar que a construção desta agenda depende da promoção de uma maior articulação do subsistema de política regional, conforme mostrado por Santos (2020b).

As estratégias possíveis para atingir estes objetivos são variadas. Um dos caminhos é utilizar as competências científicas e tecnológicas, bem como as vantagens institucionais do SRI fluminense para desenvolver vocações latentes ou já reveladas, desde que inseridas em um projeto de desenvolvimento mais amplo, diversificando a economia e adensando as cadeias produtivas já existentes. Santos (2020b) elenca alguns setores e segmentos estratégicos nos quais o estado poderia apostar, incluindo o complexo da saúde; cluster marítimo; hub logístico; turismo sustentável; economia criativa e serviços empresariais intensivos em conhecimento, com foco em audiovisual e tecnologias da informação e comunicação respectivamente.

Em relação aos serviços empresariais intensivos em conhecimento, Santos et al. (2018) destacam o potencial deste segmento para adensar as cadeias produtivas industriais presentes no estado e contribuir com o aumento da taxa de inovação e capacidade de absorção das pequenas e médias empresas, que são as principais responsáveis pelo provimento destes serviços. Além disso, os autores indicam que serviços desta natureza podem ser um caminho de dinamização das regiões localizadas no interior do estado. No entanto, é imperioso preencher lacunas na oferta de capacitação nessas regiões, principalmente naquelas que possuem estrutura industrial relevante e demandam serviços deste tipo. 
O complexo econômico-industrial da saúde, por seu turno, é apontado em diferentes estudos como um dos possíveis vetores de desenvolvimento para o SRI fluminense (Porto et al. 2012; Paranhos e Hasenclever, 2015; Anprotec, 2019). Vasconcellos et al. (2021) mostram de que maneira, a partir da base industrial já instalada no estado, seria possível criar uma estratégia de adensamento deste complexo em direção a setores de maior complexidade da indústria de transformação da Região Metropolitana do Rio de Janeiro. Além da sua importância para incremento da inovação e sofisticação produtiva, a promoção do complexo da saúde também pode ser fundamental para resolver desafios conjunturais, como a atual crise sanitária decorrente da pandemia do Covid-19, e societais, como a promoção de uma vida saudável e do bem-estar para todos; bem como reduzir a dependência tecnológica do país na produção de insumos farmacêuticos e medicamentos.

Finalmente, conforme argumentam Penna et al. (2021), as políticas setoriais ou baseadas em vocações apresentam limites, e, no contexto fluminense, não foram suficientes para promover a inovação, o adensamento produtivo e o desenvolvimento regional no estado do Rio de Janeiro. Diante disso, e em linha com as experiências internacionais, os autores propõem que o mais adequado para o SRI fluminense seria estabelecer uma Política de Inovação Orientada a Missões (cf. Mazzucato, 2018) capaz de se articular com a sociedade, endereçar problemas societais e se ajustar ao contexto de forma dinâmica, aumentando as chances de obter legitimidade política e social. Ao se desprender da lógica tradicional de setores e vocações e se estruturar em torno de grandes desafios sociais, ambientais e econômicos, este tipo de política distribui o risco, estimula a multidisciplinaridade e articula de forma dinâmica múltiplos atores, setores e tecnologias, tirando maior proveito da infraestrutura científico-tecnológica e da base produtiva existente, levando também em consideração o elemento da sustentabilidade, muitas vezes ausente nas políticas sistêmicas tradicionais.

\section{CONSIDERAÇÕES FINAIS}

O objetivo deste artigo foi caracterizar o SRI fluminense com o intuito de refletir sobre os limites e as potencialidades do ERJ para enfrentar a sua crise estrutural, que se acentuou com a pandemia da Covid-19.

Uma agenda de desenvolvimento para o estado do Rio de Janeiro voltada para o contexto pós Cóvid-19 deve, necessariamente, aproveitar as potencialidades e endereçar as fraquezas do SRI fluminense aqui apresentadas, para que a formulação de políticas explícitas 
de ciência, tecnologia e inovação seja feita de forma articulada com as políticas implícitas, de modo a atender aos desafios sociais enfrentados pelo estado.

Os caminhos são múltiplos, no entanto todos passam por fomentar a interação entre os subsistemas de geração e de exploração do conhecimento; aumentar a taxa de inovação da economia, sobretudo das pequenas e médias empresas; e se desprender da lógica puramente setorial ou de vocações, aproveitando os ativos existentes para elaborar e implementar uma política de inovação orientada a missões voltadas à solução de grandes desafios societais, econômicos e ambientais através da geração, difusão e aplicação de conhecimento científico, tecnológico e de inovação. A atual crise sanitária é um ponto de partida oportuno para estruturar uma política deste tipo.

\section{REFERÊNCIAS}

ANPROTEC - ASSOCIAÇÃO NACIONAL DE ENTIDADES PROMOTORAS DE EMPREENDIMENTOS INOVADORES. Ecossistema de Inovação - Região Metropolitana do Rio de Janeiro: Setores prioritários para o Desenvolvimento da Região. Apresentação realizada no Workshop "Desafios à Inovação: Sociedade, Empresas e Governos". Fórum Permanente de Desenvolvimento Estratégico do Estado do Rio de Janeiro, 2019.

ASHEIM, B.; GERTLER, M. The Geography of Innovation: Regional Innovation Systems. In: FAGERBERG, J.; MOWERY, D.; NELSON, R. (Eds.), The Oxford Handbook of Innovation. Oxford: Oxford University Press. 291-317, 2005.

BOSCHMA, R. Proximity and innovation. A critical assessment. Regional Studies 39(1): 61$74,2005$.

BRITTO, J; CASSIOLATO, J.E; MARCELLINO, I. S. Especialização produtiva e dinamismo inovativo da indústria fluminense: desafios e potencialidades para o desenvolvimento regional. In: OSORIO, M.; MELO, L. M.; VERSIANI, M. H; WERNECK, M. L. (Orgs). Uma agenda para o Rio de Janeiro: Estratégias e Políticas Públicas para o Desenvolvimento Socioeconômico. Rio de Janeiro: FGV: 2015.

COOKE, P. Introduction, in BRACZYK H.-J.; COOKE, P.; HEIDENREICH, M. (Eds) Regional Innovation Systems, UCL Press, London, 1998.

COOKE, P.; HEIDENREICH, M.; BRAZYCK, H. J. (Eds.) Regional innovation systems (2nd Ed.). London: Routledge, 2004.

DOLOREUX, D.; GOMEZ, I. A review of (almost) 20 years of regional innovation systems research. Europe Planning Studies, vol. 25, issue 3, pp. 381-387, 2016. 
DOLOREUX, D.; PARTO, S. Regional innovation systems: Current discourse and unresolved issues. Technology in Society, 27(2), 133-153, 2005.

FERNANDEZ, V.; COMBA, D. Sistemas Regionales de Innovación en la periferia: una perspectiva crítica. Redes - Santa Cruz do Sul: Universidade de Santa Cruz do Sul, v. 22, n. 1, janeiro-abril, 2017.

GADELHA, C. A.; GADELHA, P.; NORONHA, J. C.; PEREIRA, T. R. (Orgs.). Brasil Saúde Amanhã: Complexo Econômico-Industrial da Saúde. Rio de Janeiro, Editora Fiocruz, 2017.

GERTLER, M. Rules of the game: the place of institutions in regional economic change. Regional Studies 44, 1-15, 2010.

GUARANYS, L. Interação Universidade-Empresa e a Gestão de uma Universidade Empreendedora: A Evolução da PUC-Rio. Tese submetida ao corpo docente da coordenação dos programas de pós-graduação de engenharia da Universidade Federal do Rio de Janeiro, 2006.

GUIMARÃES, V.; PEIXOTO, F.; CASSIOLATO, J. E.; LASTRES, H. M. M. Convergências e complementaridades da corrente neo-schumpeteriana com o pensamento estruturalista de Celso Furtado. In: SABOIA, J.; CARVALHO, F.J.C. Celso Furtado e o século XXI. Rio de Janeiro: Manole e IE/UFRJ, 2007

HERRERA, A. Los determinantes sociales de la política científica em América Latina: política científica explícita y política científica implícita. In: SABATO, J.A El pensamento Latino-americano en la problemática ciencia-tecnologíadesarrollo-dependencia. Buenos Aires: Ediciones Biblioteca Nacional, 2011.

HORA, A. L. F. Avaliação da Gestão de Ambientes de Inovação: Aplicação do Amaral's Model for Innovation Environment Management (AMIEM) em Parques Tecnológicos do Estado do Rio de Janeiro. Dissertação (Mestrado) - Programa de Pós-Graduação em Administração, Instituto de Ciências Humanas e Sociais, UFF, Volta Redonda, 2019.

IBGE - INSTITUTO BRASILEIRO DE GEOGRAFIA E ESTATÍSTICA. Pesquisa de Inovação - 2017. IBGE, Coordenação de Indústria. Rio de Janeiro, 2020.

LASTRES, H. M. M.; CASSiOlATO, J. E. As Contribuições de Celso Furtado sobre o papel da Ciência, Tecnologia e Inovação ao Desenvolvimento. Cadernos do Desenvolvimento v.15 n. 26, 2020, p.277-298. Disponível em: http://www.cadernosdodesenvolvimento.org.br/ojs-2.4.8/index.php/cdes. Acesso em: 11 mar. 2021

LUNDVALL, B. A. National Systems of innovation: Towards a theory of innovation and interactive learning. Pinter, Londres, 1992. 
MARCELlinO, I. O Complexo Produtivo de P\&G como vetor para o fortalecimento do SRI Fluminense: uma análise de determinantes estruturais e organizacionais. Dissertação de mestrado defendida no programa de pós-graduação em economia da UFF, 2014.

MARCELLINO, I.; AVANCI, V.; BRITTO, J. O Sistema Regional de Inovação Fluminense: características, desafios e potencialidades. Cadernos do Desenvolvimento Fluminense, Rio de Janeiro, n.2, julho/2013.

MARCELLINO, I.; SANTOS, G. Padrões de dinamismo inovativo e estratégias empresariais de inovação no Sistema de Inovação do Rio de Janeiro. I Seminário de Economia Fluminense, Rio de Janeiro, setembro, 2017.

MAZZUCATO, M. Mission-Oriented Innovation Policies: Challenges and Opportunities. Industrial and Corporate Change, 27(5), 803-815, 2018.

MCTI - MINISTÉRIO DA CIÊNCIA, TECNOLOGIA E INOVAÇÃO. Indicadores Nacionais de Ciência, Tecnologia e Inovação - 2019. Brasília: MCTI, 2019.

METTEN, A.; COSTA, L. S.; GADELHA C. A.; MALDONADO, J. A introdução do complexo econômico industrial da saúde na agenda de desenvolvimento: Uma análise a partir do modelo de fluxos múltiplos de Kingdon. Revista de Administração Pública, Rio de Janeiro 49(4): 915-936, jul./ago. 2015.

OSÓRIO, M.; VERSIANI, M. H. O círculo vicioso do Rio de Janeiro: o que fazer? Jornal dos Economistas, n. 371, julho de 2020, p. 3-4.

PARANHOS, J; HASENCLEVER, L. Complexo da economia da saúde no Estado do Rio de Janeiro: uma oportunidade de ampliar o desenvolvimento no Estado? In: OSORIO, M.; MELO, L.M.; VERSIANI, M.H; WERNECK, M.L. (orgs). Uma agenda para o Rio de Janeiro: Estratégias e Políticas Públicas para o Desenvolvimento Socioeconômico. Rio de Janeiro: FGV: 2015.

PENNA, C. C. R.; SANTOS, G. O.; PEREIRA, M. V. G. O Papel das Agências de Inovação e Empreendedorismo na Formulação de Políticas de Inovação Orientadas a Missões: A Experiência da Diretoria de Tecnologia da FAPERJ. Revista de Administração, Sociedade e Inovação, v. 7, nº 2, 2021.

PORTO, G.; KANNEBLEY JR., S.; DIAS, A.; RADAELLI, V. O Sistema Estadual de Inovação do estado do Rio de Janeiro: uma contribuição ao diálogo de políticas entre o governo do Estado do Rio de Janeiro e o Banco Interamericano de Desenvolvimento. BID, 2012. 
SANTOS, G. Alinhamento das incubadoras de empresas ao contexto regional no estado do Rio de Janeiro: uma comparação entre metrópole e interior. Dissertação de mestrado defendida no Programa de Políticas Públicas e Estratégias de Desenvolvimento, Instituto de Economia, UFRJ, 2016.

. A relação entre incubadoras de empresas e as regiões em que se localizam no Estado do Rio de Janeiro: Uma comparação entre metrópole e interior. International Journal Of Innovation, 8(1), 101-120, 2020a.

. Caminhos para a Construção de uma Nova Trajetória de Desenvolvimento: Uma Abordagem Evolucionária do Sistema Regional de Inovação do Estado do Rio de Janeiro. Tese de Doutorado do Programa de Políticas Públicas, Estratégias e Desenvolvimento, Instituto de Economia de Universidade Federal do Rio de Janeiro, 2020b.

SANTOS, G. O.; LA ROVERE, R. Elementos para uma política de apoio ao Sistema regional de Inovação do Estado do Rio de Janeiro: Uma análise com base na abordagem da geografia econômica evolucionária. Anais do II Encontro de Economia Industrial e da Inovação. São Paulo: Blucher Proceedings, v. 4, pp. 405-423, 2017.

SANTOS, G. O. LA ROVERE, R.; ALMEIDA, E. S.; Oferta e Demanda de Capacitação para Serviços Empresariais Intensivos em Conhecimento no Estado do Rio de Janeiro. Cadernos do Desenvolvimento Fluminense, n. 14/15, 1. semestre de 2018.

SAPSED, J.; GRANTHAM, A.; DEFILLIPI, R. A bridge over troubled waters: Bridging organisations and entrepreneurial opportunities in emerging sectors. Research Policy, n. 36, pp. 1314-1334, 2007.

SOBRAL, B. A evidência da estrutura produtiva oca: o Estado do Rio de Janeiro como um dos epicentros da desindustrialização nacional. In: NETO, A. M.; CASTRO, C. N.; BRANDÃO, C. A. (orgs.) Desenvolvimento regional no Brasil: políticas, estratégias e perspectivas. Rio de Janeiro: IPEA, 2017.

STORPER, M. Regional Economies as Relational Assets. In: LEE, R.; WILLS, J. (Eds.), Geographies of Economies, Arnold, New York, 1997.

TÖDTLING, F.; TRIPPL, M. One Size Fits All? Towards a Differentiated Regional Innovation Policy Approach. Research Policy, 34, 8: 1203-1219, 2005.

UYARRA, E. What is evolutionary about 'regional systems of innovation'? Implications for regional policy. Journal of Evolutionary Economics, 20, 115-137, 2010.

VASCONCELlOS, B. L. X.; LA ROVERE, R. L.; PEREIRA, R. S.; SANTOS, G. O. A Complexidade Econômica como caminho de diversificação para a Região Metropolitana do 
Rio de Janeiro: implicações para o complexo industrial da saúde. Artigo aprovado para ser apresentado no V Encontro Nacional de Economia Industrial e da Inovação (ENEI) Inovação, Sustentabilidade e Pandemia, FACE, UFMG, 2021. 